\title{
Deterioration of metal-organic framework crystal structure during fabrication of poly(L-lactic acid) mixed-matrix membranes
}

\author{
Ajay Kathuria, ${ }^{a}$ Mohamad G Abiad ${ }^{b}$ and Rafael Auras ${ }^{a} *$
}

\begin{abstract}
Poly(L-lactic acid) (PLLA) and metal-organic framework (MOF) mixed-matrix membranes were prepared by melt extrusion of PLLAwith5\%(w/w) of either activated or water-saturated $\mathrm{Cu}_{3}(\mathrm{BTC})_{2}\left(\mathrm{Cu}_{3}\left(\mathrm{C}_{9} \mathrm{H}_{3} \mathrm{O}_{6}\right)_{2}\left(\mathrm{H}_{2} \mathrm{O}\right)_{3}-\mathrm{xH}_{2} \mathrm{O}\right.$, HKUST-1).The morphology and the stability of injection-molded samples were evaluated using thermogravimetric analysis, differential scanning calorimetry, gel permeation chromatography, X-ray diffraction (XRD) and scanning electron microscopy (SEM). The presence of activated and saturated MOF crystals increased the cold crystallization onset temperature as compared to neat PLLA. This can be attributed to the MOF crystals incorporated in the PLLA matrix, which decreased the mobility of PLLA and thus impeded the crystallization process. According to the XRD results, the activated MOF crystals were successfully incorporated into the PLLA matrix without altering the crystal structure of the MOF. Moreover, the findings from permeability and tensile tests as well as SEM imaging indicated good interfacial interactions between PLLA and activated MOF. However, during melt extrusion of PLLA with saturated MOF, water molecules from the saturated MOF altered the MOF crystal structure and contributed to the degradation of the PLLA polymer by reducing its molecular weight by around $21 \%$.
\end{abstract}

\section{INTRODUCTION}

During the last couple of decades, growing environmental concerns along with limited petroleum resources and technological improvements have provided impetus to the development of new bio-based, biodegradable and compostable polymers such as poly(lactic acid) (PLA). Due to technological advancements, PLA has become one of the most remarkable commercial polymers in this category, particularly for medical and packaging applications. ${ }^{1,2}$

PLA is generally synthesized by ring-opening polymerization of lactide monomers which are linked together in one of three isomeric forms: D,D-lactide, L,L-lactide and D,L-lactide. The final properties of the PLA, such as thermal, mechanical and barrier properties, are significantly affected by the isomeric composition of the resin. Although PLA has many appealing properties such as transparency, low processing temperature and compostability, it is brittle and has low heat deflection temperature which limits the scope of its application.Consequently, researchers have attempted to use different methodologies including plasticization, chemical modification, composite fabrication and blending to reduce PLA's inherent brittle nature andimprove its heat deflection temperature and gas and water vapor barrier properties among others. ${ }^{3-6}$

Metal-organic frameworks (MOFs) are a class of crystalline materials with high porosity, which are composed of metal ions $\left(\mathrm{Cu}+, \mathrm{Cu}^{2+}, \mathrm{Ag}+, \mathrm{Zn}^{2+}, \mathrm{Co}^{2+}, \mathrm{K}+\right.$, etc.) linked together by organic bridging ligands forming single- or multi-dimensional structures. ${ }^{7}$ They exhibit high thermal and mechanical stability. ${ }^{8}$ Perhaps the most attractive properties of MOFs are their ultrahigh surface areas, which are greater than those of porous carbons or zeolites and may exceed at times $5900 \mathrm{~m}^{2} \mathrm{~g}^{-1}, 9$ large pore sizes and high micro-pore volume. The porosity and large surface area of these materials along with their varied chemical compositions render them candidates for high-capacity adsorption of various gases and molecules. ${ }^{10}$ The structure of MOFs allows guest molecules to diffuse into the bulk structure while the size, shape and affinity of these pores provide selectivity among the guests, which can be incorporated into them. There is a plethora of literature investigating the various applications of MOFs in the fields of catalysis, ${ }^{11}$ gas purification and separation, ${ }^{12}$ hydrogen storage ${ }^{13}$ and efficient controlled drug delivery. ${ }^{14}$

One of the commercially available MOFs is $\mathrm{Cu}_{3} \mathrm{BTC}_{2}$ $\left(\mathrm{Cu}_{3}\left(\mathrm{C}_{9} \mathrm{H}_{3} \mathrm{O}_{6}\right)_{2}\left(\mathrm{H}_{2} \mathrm{O}\right)_{3}\right.$, also known as HKUST-1). $\mathrm{Cu}_{3} \mathrm{BTC}_{2}$ is characterized by a face centered cubic (FCC) cell as the repeating unit. ${ }^{15}$ The $\mathrm{Cu}^{2+}$ dimer coordinated with four oxygen atoms of benzene tricarboxylate makes a paddle wheel which constitutes the building block of HKUST-1, whose structure is represented in Fig. 1. ${ }^{15}$ The water molecules axially coordinated to the two exchangeable copper sites can be removed by heat activation under vacuum yielding a Lewis acid site with catalytic properties. ${ }^{16}$

*Correspondence to: Rafael Auras, School of Packaging, Packaging Building, Michigan State University, East Lansing, MI, 48824-1223, USA. E-mail:aurasraf@msu.edu

a School of Packaging, Packaging Building, Michigan State University, East Lansing, MI, 48824-1223, USA

b Department of Nutrition and Food Science, American University of Beirut, Beirut, Lebanon 

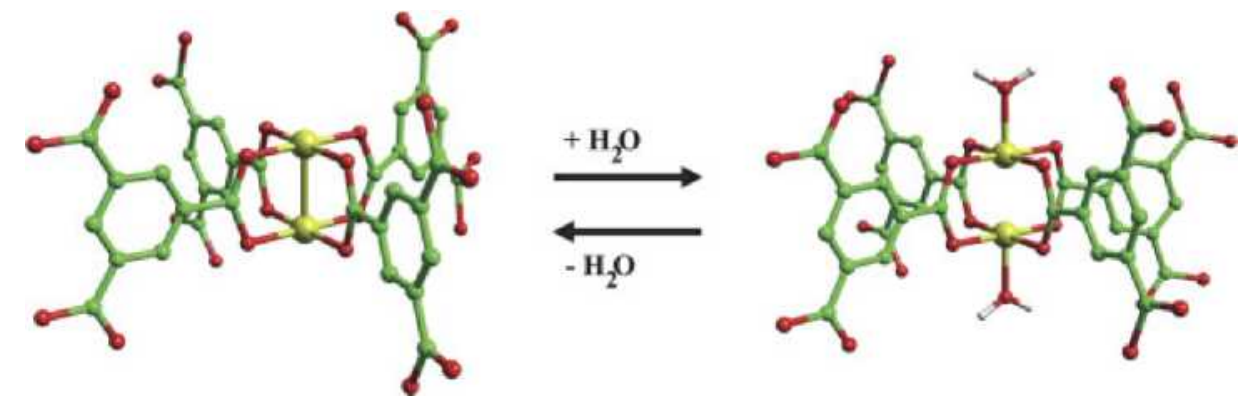

Figure 1. Schematic of the building blocks of dehydrated HKUST-1. Left: $\mathrm{CU}_{2} \mathrm{C}_{4} \mathrm{O}_{8}$ dehydrated structure, two Cu${ }^{2+}$ ions and four benzene-1,3,5tricarboxilate linkers are bonded to provide the paddle wheel three-dimensional structure. Right: after water uptake the $\mathrm{Cu}_{2} \mathrm{C}_{4} \mathrm{O}_{8}$ cage is hydrated. $\mathrm{Cu}_{2} \mathrm{C}_{4} \mathrm{O}_{8}$ cage: $\mathrm{Cu}^{2+}$, yellow; $\mathrm{O}$, red; $\mathrm{C}$, green; $\mathrm{H}$, gray. (Adapted after Bordiga et al. ${ }^{15}$ Chemical structures drawn using Moilin molecular modeling software. ${ }^{17}$ )

Interest in improving the functionality of polymer-based membranes has led researchers to develop new mixed-matrix membranes (MMMs) by integrating inorganic, organic and hybrid particles such as zeolites, MOFs, carbon and carbon nanotubes, among other sieving materials, within organic matrices. ${ }^{18-23}$ The thermal and mechanical stabilities are key factors in the development of such systems. For this reason, the aim of the study reported here was to understand the effect of the adsorbed water present in CuzBTC2 MOF on the morphology and stability of $\mathrm{MMMs}$ based on poly (L-lactic acid) (PLLA)- $\mathrm{Cu}_{3} \mathrm{BTC}_{2}$ prepared by melt extrusion followed by injection molding.

\section{METHODOLOGY \\ Materials}

PLLA resin grade 4043 D, 98\% L-lactide, with weight-average molecular weight $\left(M_{w}\right)$, number-average molecular weight $\left(M_{n}\right)$ and polydispersity index $\left(\mathrm{M}_{\mathrm{w}} / \mathrm{M}_{\mathrm{n}}\right)$ of $111 \mathrm{~kg} \mathrm{~mol}^{-1}, 84 \mathrm{~kg} \mathrm{~mol}^{-1}$ and 1.3 , respectively, was procured from NatureWorks LLC (Minnetonka, MN, USA). Trimesic acid (TMA) or benzene-1,3,5tricarboxylic acid (95 wt\% pure) and Basolite ${ }^{\mathrm{TM}}$ C300 MOF (Cu3BTC2) were purchased from Sigma Aldrich (St Louis, MO, USA). The BET surface area of $\mathrm{Cu}_{3} \mathrm{BTC}_{2}$ MOF as reported by the manufacturer ranges between 1500 and $2100 \mathrm{~m}^{2} \mathrm{~g}^{-1}$, and was previously measured as $1566 \mathrm{~m}^{2} \mathrm{~g}^{-1} \cdot{ }^{24}$ The particle size of $\mathrm{Cu}_{3} \mathrm{BTC}_{2}$ averages $15 \mu \mathrm{m}$ measured using a JEOL JSM 6400 SEM instrument (Japan Electron Optics Laboratories Ltd, Tokyo, Japan) with an accelerating voltage of $12 \mathrm{kV}$ and $39 \mathrm{~mm}$ working distance (Fig. 2). The detailed methodology for SEM is provided below.

\section{Sample preparation}

Prior to processing and extrusion, the PLLA resin was dried at $80{ }^{\circ} \mathrm{C}$ for $4 \mathrm{~h}$. Activated $\mathrm{Cu}_{3} \mathrm{BTC}_{2}$ MOF - referred to here as 'activated MOF' - was activated for $24 \mathrm{~h}$ at $200{ }^{\circ} \mathrm{C}$ using a vacuum oven. In contrast, saturated $\mathrm{Cu}_{3} \mathrm{BTC}_{2} \mathrm{MOF}$ - referred to here as 'saturated MOF' - was obtained by conditioning at $23{ }^{\circ} \mathrm{C}$ and $50 \%$ relative humidity $(\mathrm{RH})$ for four days to equilibrate and reach water storage capacity. This time period was predetermined to be sufficient for the MOF to saturate and stabilize. ${ }^{25}$

MMMs (PLLA + 5 wt\% MOF) were extruded using a vertical corotating twin-screw micro-compounder (DSM Research, Geleen, The Netherlands) followed by injection molding. The extruder was equipped with two $150 \mathrm{~mm}$ screw and $L / D$ ratio of 18 . The volume of

the barrel was approximately $15 \mathrm{~cm}^{3}$. The extruded compositions were transferred into a transferring cylinder and injected into a

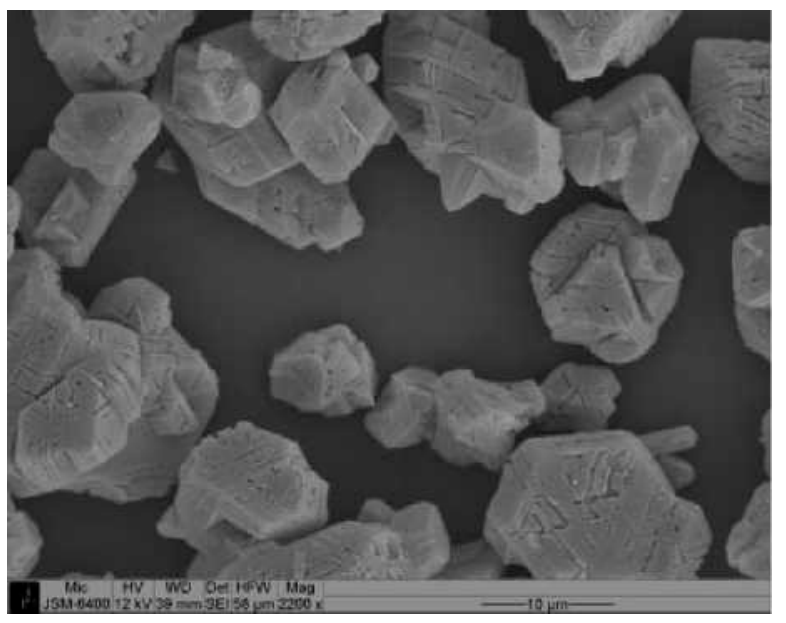

Figure 2. SEM image of Basolite ${ }^{\mathrm{TM}} \mathrm{C} 300$ acquired at $12 \mathrm{kV}$ and $39 \mathrm{~mm}$ working distance.

mini-injection molder (DSM Research). The temperature profile for the extrusion process from the top to bottom zone was set at $190{ }^{\circ} \mathrm{C}$ with an extrusion cycle time of $5 \mathrm{~min}$. The pressure for injection molding was ca $1 \mathrm{MPa}(140 \mathrm{psi})$ while the transfer cylinder and mold temperatures were set at 195 and $65{ }^{\circ} \mathrm{C}$, respectively. Dog-bone tensile bars and XRD discs of PLLA and PLLA-5\% activated MOF (PLLA-A-MOF) and PLLA-5\% saturated MOF (PLLA-S-MOF) composites were prepared and stored in a desiccator over a desiccant (Drierite ${ }^{\circledR}$ ) at room temperature (ca 23 ${ }^{\circ} \mathrm{C}$ ). A MOF content of $5 \mathrm{wt} \%$ was previously determined as enough to produce a meaningful change in the final thermal, mechanical and barrier properties of the MMMs. ${ }^{24,25}$

\section{Characterization}

Thermogravimetric analysis

The thermal stability of $\mathrm{Cu}_{3} \mathrm{BTC}_{2}$ MOF, PLLA and PLLA-MOF composites was examined using TGA (model 2950,TA Instruments, New Castle, DE, USA). TGA was also used to determine the initial water content in the $\mathrm{Cu}_{3} \mathrm{BTC}_{2}$ MOF. Approximately $5 \mathrm{mg}$ of sample was heated from 23 to $700{ }^{\circ} \mathrm{C}$ at a rate of $10{ }^{\circ} \mathrm{Cmin}^{-1}$. The TGA data were analyzed using Universal Analysis software version 2000 (TA Instruments). Sample runs were carried out in triplicate.

\section{$X$-ray diffraction}

XRD data were collected for the injection-molded XRD discs of PLLA, PLLA-A-MOF and PLLA-S-MOF stored at $23^{\circ} \mathrm{C}$ in a desiccator 
as well as for activated and saturated $\mathrm{Cu}_{3} \mathrm{BTC}_{2}$ MOF powder using a Bruker D8 advance X-ray diffractometer (Bruker AXS GmbH, Karlsruhe, Germany) at $40 \mathrm{kV}, 40 \mathrm{~mA}$ (1600 W) using $\mathrm{Cu} \mathrm{K \alpha}$ radiation $(\lambda=1.5418 \AA$ ), with a $1.2 \mathrm{~mm}$ primary beam slit and $2.0 \mathrm{~mm}$ detector slit. The $\mathrm{X}$-ray scans were carried out at a rate of $0.02^{\circ} \mathrm{s}^{-1}$. Data were collected in triplicate.

\section{Differential scanning calorimetry}

DSC analysis was performed using a DSC Q100 from TA Instruments. The samples were equilibrated to $0{ }^{\circ} \mathrm{C}$ followed by heat/cool/heat cycles from 0 to $180{ }^{\circ} \mathrm{C}$ at a rate of $10^{\circ} \mathrm{Cmin}^{-1}$. The melting temperature $\left(T_{m}\right)$ and associated heat enthalpy $\left(\Delta H_{m}\right)$ were computed from the first heating cycle. In contrast, the glass transition temperature $\left(T_{\mathrm{g}}\right)$,cold crystallization onset temperature $\left(T_{c o}\right)$, cold crystallization peak temperature $\left(T_{c c}\right)$ and enthalpy of cold crystallization $\left(\Delta H_{c}\right)$ were calculated from the second heat cycle to eliminate any thermal history caused by processing or storage. DSC data were obtained in triplicate and were analyzed using Universal Analysis software version 2000.

The percentage crystallinity of the samples was determined

using

$$
X_{c}(\%)=\frac{\Delta H_{m}-\Delta H_{c}}{\Delta H_{m}^{c}(1-x)} \times 100
$$

where $\Delta H_{m}$ is the enthalpy of fusion; $\Delta H_{c}$ is the enthalpy of cold crystallization; $\Delta H_{m}^{c}, 93.1 \mathrm{~J} \mathrm{~g}^{-1},{ }^{26}$ is the enthalpy of fusion of pure crystalline PLA; and $x$ is the mass fraction of the MOF in the MMM.

\section{Tensile tests}

Tensile properties were evaluated according to ASTM D638-10 using a universal tensile machine (model UTS SFM 20, United Calibration Corporation, Huntington Beach, CA, USA).The machine was equipped with a laser extensometer. Injection-molded dogbone samples with a gauge length of $25.4 \mathrm{~mm}$ were stored at room temperature in a desiccator over desiccant (Drierite ${ }^{\circledR}$ ) for $40 \mathrm{~h}$ prior to testing. The samples were then tested at room temperature (ca $23^{\circ} \mathrm{C}$ ) using a $453 \mathrm{~kg}$ load cell at $0.023 \mathrm{~kg}$ of preload. PLLA and PLLA-MOF composites were tested at a crosshead speed of 50.8 $\mathrm{mm} \min ^{-1}\left(2\right.$ in $\mathrm{min}^{-1}$ ), whereas PLLAand PLLA-TMAcomposites were tested at a crosshead speed of $2.54 \mathrm{~mm} \mathrm{~min}^{-1}\left(0.1 \mathrm{in} \mathrm{min}^{-1}\right)$ (discussed in more detail in a later section). At least five replicates were tested for each type of sample.

\section{Weight-average molecular weight}

In order to examine the effect of processing conditions and water content of the $\mathrm{Cu}_{3} \mathrm{BTC}_{2}$ MOF on the molecular weight of the PLLA matrix, $M_{w}$ and $M_{n}$ of the PLLA resin, extruded PLLA resin, PLLA-A-MOF and PLLA-S-MOF were determined using a gel permeation chromatography (GPC) instrument (Waters Inc., Milford, MA, USA). A flow rate of $1 \mathrm{mLmin}^{-1}$ and runtime of $45 \mathrm{~min}$ at $35{ }^{\circ} \mathrm{C}$ were used. The instrument was calibrated with polystyrene

standard materials with a molecular weight ranging from $2.9 \times 10^{3}$ to $3.64 \times 10^{6} \mathrm{gmol}^{-1}$ using a third-order polynomial equation. The Mark-Houwink corrected constant $K=0.000174 \mathrm{mLg}^{-1}$ and $a=0.736$ for dilute PLLA solution in tetrahydrofuran (THF) were used. ${ }^{27}$ The instrument was equipped with a Waters 1515 isocratic pump, a Waters 717 autosampler, a series of Waters Styragel columns (HR4, HR3 and HR2) and a Waters 2414 refractive index detector. Approximately $20 \mathrm{mg}$ of specimen was dissolved in $10 \mathrm{~mL}$ of HPLC-grade THF with $99.99 \%$ purity (Pharmco-Aaper, Brookfield, $C T, U S A)$ in order to determine $M_{w}, M_{n}$ and polydispersity index. The solution was then filtered with a $0.45 \mu \mathrm{m}$ filter.
Scanning electron microscopy

A JEOL JSM 6400 SEM instrument equipped with a lanthanum hexaboride $\left(\mathrm{LaB}_{6}\right)$ electron gun was utilized to study the surface topography of PLLA, $\mathrm{Cu}_{3} \mathrm{BTC}_{2}$ MOF, PLLA-A-MOF and PLLA-S-MOF. The samples were sputter-coated with gold $(10 \mathrm{~nm})$ using an Emscope SC 500 (Emscope Laboratories Ltd, Ashford, UK). SEM photomicrographs were acquired at an accelerating voltage of $12 \mathrm{kV}$.

\section{$\mathrm{CO}_{2}$ and $\mathrm{O}_{2}$ permeability coefficients}

Films used for permeability studies were prepared using a $\mathrm{PHI} 30$ ton compression molding machine (City of Industry, CA, USA) with a plate size of $30 \mathrm{~cm} \times 30 \mathrm{~cm}$. Injection-molded samples prepared using the twin-screw DSM micro-compounding instrument were compressed at $170{ }^{\circ} \mathrm{C}$ and $\mathrm{ca} 1.0 \mathrm{MPa}$ for $5 \mathrm{~min}$. The $\mathrm{CO}_{2}$ and $\mathrm{O}_{2}$ permeation rates were measured using a Permatran ${ }^{\text {TM }}$ C 4/41 and an Oxtran ${ }^{\mathrm{TM}}$ 2/21 (MOCON Inc., Minneapolis, MN, USA), respectively, at $23{ }^{\circ} \mathrm{C}$ and $0 \% \mathrm{RH}$, with $100 \%$ permeant gas between aluminium masks with areas of 3.14 and $5 \mathrm{~cm}^{2}$. The permeability coefficients of $\mathrm{CO}_{2}$ and $\mathrm{O}_{2}$ were calculated using

$$
\text { Permeability }=\text { gas transmission rate } \times(1 / \Delta P) \times t
$$

where $\Delta P$ is the difference in permeant partial pressure across the films expressed in $\mathrm{Pa}$ and $t$ is the film thickness.

\section{Data analysis}

Statistical analyses were performed using SAS 9.0 software (SAS Institute Inc., Cary, NC, USA). Tukey's HSD (honestly significant differences) tests were used to determine significance at $95 \%$ confidence $(\alpha=0.05)$.

\section{RESULTS AND DISCUSSION}

\section{Thermogravimetric analysis}

The TGA thermographs for activated MOF, saturated MOF, PLLA, PLLA-A-MOF and PLLA-S-MOF are shown in Fig. 3. According to the obtained results, the saturated MOF which was stored at $23{ }^{\circ} \mathrm{Cand}$ $50 \% \mathrm{RH}$ for four days adsorbs around $36 \%(\mathrm{w} / \mathrm{w})$ moisture while the activated MOF adsorbs $5 \%(\mathrm{w} / \mathrm{w})$ moisture mostly attributed to water adsorbed during sample handling. Schlichte etal. ${ }^{28}$ obtained similar results for HKUST- 1 dried in a vacuum oven at $100{ }^{\circ} \mathrm{C}$ and rehydrated in both air and moist argon stream as they reported 2, 27 and $36.4 \%$ (w/w) moisture; respectively.

Figure 3 also shows that the organic component of the MOF, benzene tricarboxylate, starts degrading at around $325{ }^{\circ} \mathrm{C}$. The thermal degradation onset of the polymer matrix (PLLA) and the MMM (PLLA-A-MOF and PLLA-S-MOF) starts at around $322{ }^{\circ} \mathrm{C}$. A slight difference can be observed in the final decomposition temperature $\left(T_{d}\right)$ for PLLA, PLLA-S-MOF and PLLA-A-MOF: 385,410 and $500{ }^{\circ} \mathrm{C}$, respectively. The final plateau for PLLA-A-MOF and PLLA-S-MOF can be mainly attributed to the copper present in the MOF.

Huang et al. ${ }^{29}$ studied the thermal stability of $\mathrm{Cu}_{3} \mathrm{BTC}_{2} \mathrm{MOF}$ using ReaxFF reactive molecular dynamics. They reported good thermal stability of the MOF structure for temperatures up to $300{ }^{\circ} \mathrm{C}$ while observing structural collapse at temperatures above $327{ }^{\circ} \mathrm{C}$. The simulation from 327 to $427{ }^{\circ} \mathrm{C}$ indicated that the MOF retained its molecular formula but lost the microporous nature of the material as further heating released $\mathrm{CO} 2$ and $\mathrm{CO}$. 


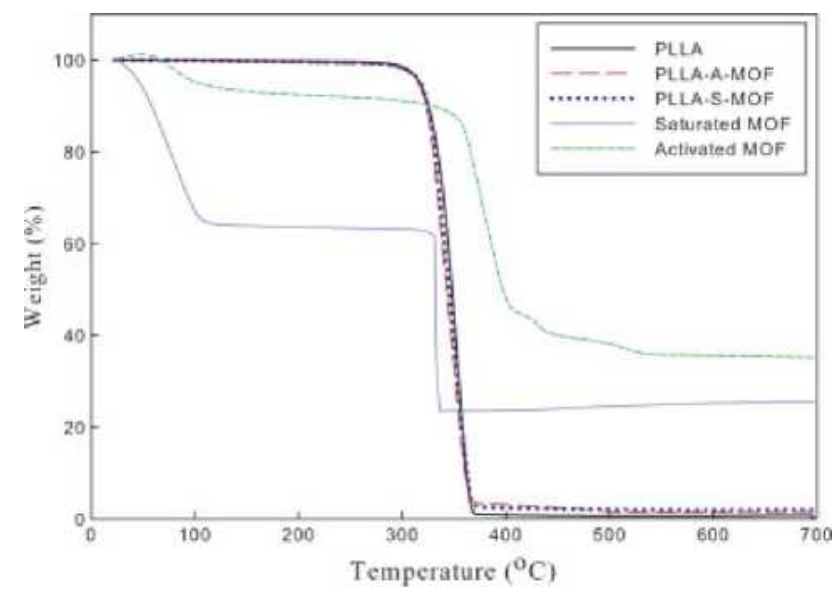

Figure 3. TGA thermograms of PLLA, PLLA-A-MOF, PLLA-S-MOF, saturated and activated MOF before extrusion.

\section{$X$-ray diffraction}

XRD patterns of activated MOF and saturated MOF are shown in Figs 4(a) and (b), respectively, matching previously reported XRD patterns. ${ }^{28,30,31}$ The intensities of various planes are given in Table 1. The data presented in this study confirm the observations previously reported by Schlichte et $a !^{28}$ regarding the intensity ratios $I_{200} / I_{220}$ and $I_{331} / I_{420}$ which are significantly higher for activated MOF than for saturated MOF as observed. The crystals retain all the planes of the FCC crystal structure. The changes in the intensity ratio of planes (200), (400) and (441) are due to the adsorption of water by the $\mathrm{Cu}_{3} \mathrm{BTC}_{2}$ MOF crystals. ${ }^{28}$ Figures5(a)-(c) show the diffractograms of PLLA-A-MOF, PLLA-S-MOF and PLLA XRD discs, respectively. The crystalline peak observed for PLLA (Fig. 5(c)) at $2 \theta=16.4^{\circ}$ corresponds to $\alpha$-PLLA crystals with a broader background hump, suggesting primarily amorphous nature of the polymer. ${ }^{32-34}$ The high amorphous content of the injection-molded PLLA, PLLA-A-MOF and PLLA-S-MOF composites can be ascribed to the slow crystallization kinetics of PLLA. ${ }^{35}$ This observation is further endorsed by the DSC analysis discussed in the next subsection. The XRD pattern of injection-molded PLLAA-MOF disc is shown in Fig. 5(a). PLLA-A-MOF shows similar peaks with minor changes in the intensity ratios calculated from the area under the curve at the same planes as observed for the $\mathrm{Cu}_{3} \mathrm{BTC}_{2}$ MOF presented in Table 2 . The extensive change in the intensity ratio of plane (200) in the case of activated MOF and PLLA-A-MOF may be related to the possible hydration of MOF during sample handling after MMM fabrication.

The $d$-spacing, peak intensity and area under the peak for various planes of PLLA-S-MOF are presented in Table 2 . It can be observed that peaks (111) and (200) which are present in the saturated MOF pattern are absent in the PLLA-S-MOF pattern and the peak intensities of other planes such as (220) and (222) are also markedly reduced. The absence of these peaks in the PLLA-S-MOF diffraction pattern indicates that saturated $\mathrm{Cu}_{3} \mathrm{BTC}_{2}$ MOF loses the FCC crystal structure after extrusion. The loss of FCC crystal structure of the MOF during compounding of the composites can be attributed to the exposure to both moisture and temperature during extrusion. Prestipino et $a ! .^{36}$ utilized a combination of extended X-ray absorption fine structure, X-ray absorption near edge structure, UV-visible and infrared spectral techniques and reported that the water sorption properties of HKUST-1 are provided by 'an open framework with an intersecting 3D-channel system - composed by dimeric cupric tetracarboxylate'. The
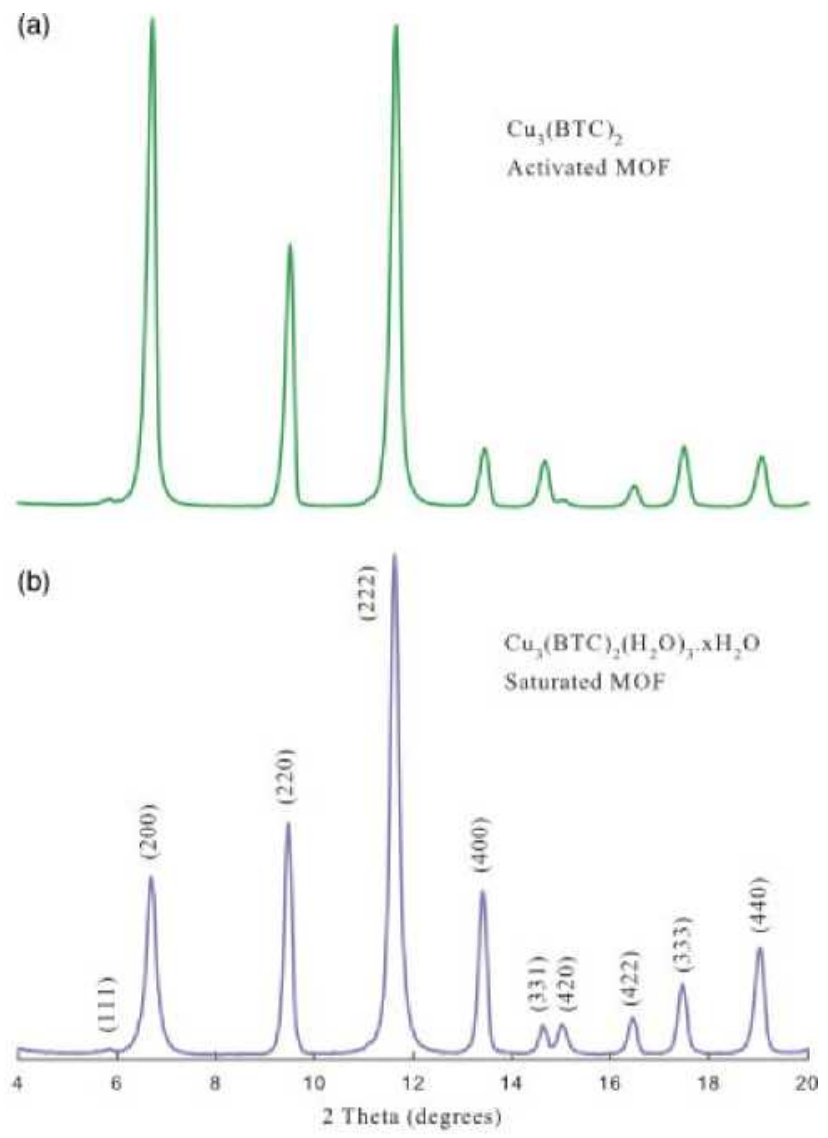

Figure 4. XRD patterns of (a) activated MOF and (b) saturated MOF.

Table 1. XRD intensities of activated and saturated MOF

Intensity ratio

Plane $20\left(^{\circ}\right) \quad$ d-spacing (A) Activated MOF Saturated MOF

\begin{tabular}{|ccccr}
\hline$(11)$ & 5.7 & 15.5 & 1.1 & 0.9 \\
$(200)$ & 6.6 & 13.5 & 97.8 & 35.2 \\
$(220)$ & 9.5 & 9.3 & 52.8 & 46.0 \\
$(222)$ & 11.6 & 7.6 & 100 & 100 \\
$(400)$ & 13.5 & 6.6 & 12 & 32.4 \\
$(331)$ & 14.6 & 6.1 & 9.5 & 5.5 \\
$(420)$ & 15.0 & 5.9 & 1.2 & 5.8 \\
$(422)$ & 16.4 & 5.4 & 4.3 & 7.1 \\
$(333)$ & 17.4 & 5.1 & 12.4 & 13.8 \\
$(440)$ & 19.0 & 4.7 & 10.3 & 20.8 \\
& & & & \\
\hline
\end{tabular}

tetracarboxylate and the benzene rings in the MOF (Fig. 1(b)) are responsible for the sorption properties. Prestipino eta!. ${ }^{36}$ also reported that the adsorption properties of HKUST-1 are not only given by unspecific van derWaals interactions, but also by specific Coulomb-type electrostatic interactions. They demonstrated that, upon dehydration at $453 \mathrm{~K}$ under vacuum, the first coordination sphere of $\mathrm{Cu}^{2+}$ sites is significantly altered. The shortening of the $\mathrm{Cu}-\mathrm{Cu}$ distance and the distortion of the $\mathrm{Cu}-\mathrm{O}$ bonds produce coordinately unsaturated $\mathrm{Cu}^{2}+$ dimer sites overlooking the cages. Kusgens et al. ${ }^{27}$ also studied the water stability of $\mathrm{Cu}_{3} \mathrm{BTC}_{2}$ (HKUST-1) MOF at elevated temperatures by dipping the MOF particles into deionized water at $50^{\circ} \mathrm{C}$ for $24 \mathrm{~h}$. After filtering and 

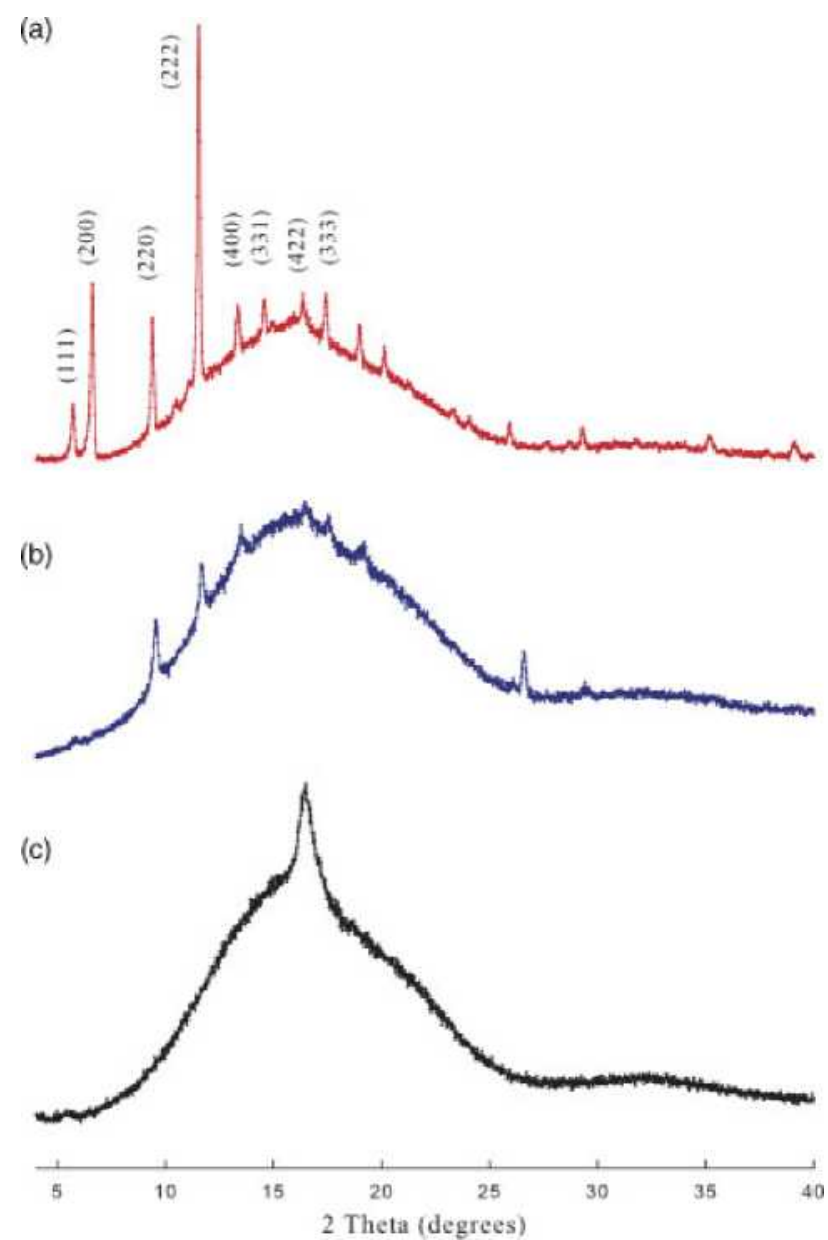

Figure 5. XRD patterns of (a) PLLA-A-MOF disc, (b) PLLA-S-MOF disc, and ( c) injection molded PLLAdisc.

drying the MOF at room temperature they performed XRD studies and evaluated the surface area demonstrating the presence of irreversible changes in the MOF structure along with a reduction in BET surface area from 1340 to $647 \mathrm{~m}^{2} \mathrm{~g}^{-1}{ }^{37}$ Mustafa et al. ${ }^{38}$ studied the stability of $\mathrm{Cu}_{3} \mathrm{BTC}_{2}$ MOF under steam conditions. They observed changes in the MOF structure starting at $70{ }^{\circ} \mathrm{C}$, with the formation of unidentified low crystalline material at $120{ }^{\circ} \mathrm{C}$. The $\mathrm{Cu}_{3} \mathrm{BTC}_{2}$ MOF transformed completely to an irreversible form, $\left[\mathrm{Cu}_{2} \mathrm{OH}(\mathrm{BTC})\left(\mathrm{H}_{2} \mathrm{O}\right)\right]_{n} \cdot 2 n \mathrm{H}_{2} \mathrm{O}$, at $150{ }^{\circ} \mathrm{C}$. The alterations in the crystal structure during processing attributed to the presence of adsorbed water in the saturated $\mathrm{Cu}_{3} \mathrm{BTC}_{2} \mathrm{MOF}$ embedded in the PLLA may lead to permanent changes in the pore size and sorption capacities of the final MMMs.

\section{Differential scanning calorimetry}

Figures 6(a) and (b) show thermograms of injection-molded PLLA, PLLA-A-MOFand PLLA-S-MOF obtained during the first and second heating cycles, respectively. A summary of the glass transition, crystallization and melting enthalpies and temperatures is given in Table 3. The average percentage crystallinities of PLLA, PLLAA-MOF and PLLA-S-MOF obtained from the second heating cycle are 2.0, 1.0 and $0.6 \%$, respectively, suggesting the amorphous nature of PLLA, PLLA-A-MOF and PLLA-S-MOF composites and complementing the observations from the XRD spectra. The mass fraction percentage crystallinity of PLLA and PLLA-A-MOF
Table 2. Intensity ratios and areas under the curve for PLLA-A-MOF and PLLA-S-MOF

PLLA-A-MOF PLLA-S-MOF

\begin{tabular}{|c|c|c|c|c|c|}
\hline \multirow[b]{2}{*}{ Plane $\left({ }^{\circ}\right)$} & \multirow{2}{*}{$\begin{array}{l}2 \theta \\
d \text {-spacing } \\
\text { (A) }\end{array}$} & \multicolumn{2}{|c|}{ Area under Intensity } & \multicolumn{2}{|c|}{ Area under Intensity } \\
\hline & & the curve ${ }^{a}$ & ratio & the curve $\mathrm{a}^{\mathrm{a}}$ & ratio \\
\hline (111) 5.7 & 15.5 & 195 & 19.8 & & \\
\hline (200) 6.6 & 13.5 & 661 & 59.9 & - & - \\
\hline (220) 9.4 & 9.4 & 348 & 47.0 & 68 & 51.5 \\
\hline (222) 11.5 & 7.7 & 1172 & 100 & 132 & 100 \\
\hline (400) 13.4 & 6.6 & 136 & 14.5 & 25 & 47 \\
\hline (331) 14.6 & 6.1 & 79.5 & 5.3 & - & - \\
\hline (420) 15.0 & 5.9 & - & - & - & - \\
\hline (422) 16.4 & 5.4 & 53 & 4.7 & 17.95 & 14 \\
\hline (333) 17.4 & 5.1 & 128 & 9.0 & - & - \\
\hline (440) 19.0 & 4.7 & 167.5 & 15.8 & & \\
\hline
\end{tabular}

${ }^{\mathrm{a}}$ Background subtracted intensity.
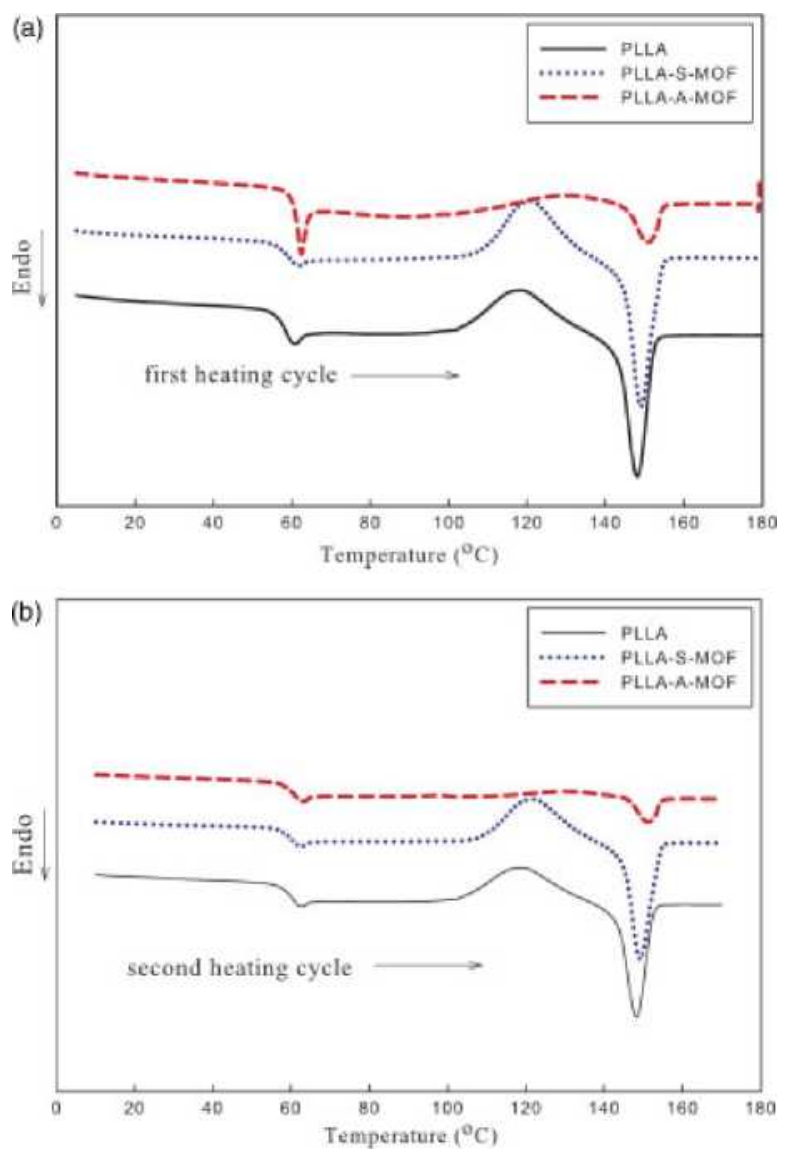

Figure 6. DSC thermograms of PLLA, PLA-A-MOF and PLA-S-MOF: (a) first heating cycle; (b) second heating cycle.

as calculated from the XRD patterns are 2.8 and $0.6 \%$, respectively. The presence of activated MOF particles slightly reduces the crystallinity of the MMMs when compared to neat PLLA.

The addition of 5 wt\% activated MOF and saturated MOF increases $T_{c o}$ and $T_{c c}$. For PLLA-A-MOF, $T_{c o}$ increases from 103.8 to $113.8{ }^{\circ} \mathrm{C}$ and $\mathrm{T}_{\mathrm{cc}}$ from 119.1 to $129.8{ }^{\circ} \mathrm{C}$; for PLLA-S-MOF, $\mathrm{T}_{\text {co }}$ increases from 103.8 to $109.8^{\circ} \mathrm{C}$ and $\mathrm{T}_{\mathrm{cc}}$ from 119.1 to $123.7^{\circ} \mathrm{C}$. 
Table 3. Detailed DSC analysis data for PLLA and its composites ${ }^{a}$

\begin{tabular}{|c|c|c|c|c|c|c|c|}
\hline \multirow[b]{2}{*}{ Sample } & \multirow[b]{2}{*}{$\mathrm{Tg}\left({ }^{\circ} \mathrm{C}\right)$} & \multicolumn{3}{|c|}{ Cold crystallization } & \multicolumn{3}{|c|}{ Melting } \\
\hline & & $\mathrm{T}_{\mathrm{co}}\left({ }^{\circ} \mathrm{C}\right)$ & $\operatorname{Tcc}\left({ }^{\circ} \mathrm{C}\right)$ & $\Delta \mathrm{Hc}_{\mathrm{c}}\left(\mathrm{Jg}^{-1}\right)$ & $T \operatorname{mo}\left({ }^{\circ} \mathrm{C}\right)$ & $T \mathrm{~m}\left({ }^{\circ} \mathrm{C}\right)$ & $\Delta \mathrm{Hm}_{\mathrm{m}}\left(\mathrm{Jg}^{-1}\right)$ \\
\hline PLLA & $60.8 \pm 0.1^{A}$ & $103.8 \pm 0.2^{A}$ & $119.1 \pm 0.1^{\mathrm{A}}$ & $19.6 \pm 0.9^{A}$ & $143.3 \pm 0.1^{A}$ & $147.9 \pm 0.2^{A}$ & $21.9 \pm 0.5^{A}$ \\
\hline PLLA-A-MOF & $60.9 \pm 0.0^{A}$ & $113.8 \pm 0.2^{\mathrm{B}}$ & $129.8 \pm 0.4^{\mathrm{B}}$ & $3.6 \pm 0.1^{\mathrm{B}}$ & $145.5 \pm 0.1^{\mathrm{B}}$ & $150.8 \pm 0.1^{\mathrm{B}}$ & $6.9 \pm 0.3^{B}$ \\
\hline PLLA-S-MOF & $59.8 \pm 0.4^{B}$ & $109.8 \pm 0.6^{c}$ & $123.7 \pm 1.5^{c}$ & $25.0 \pm 0.9^{c}$ & $145.0 \pm 0.3^{c}$ & $149.2 \pm 0.4^{c}$ & $27.2 \pm 2.1^{c}$ \\
\hline
\end{tabular}

${ }^{a}$ Values in the same column with the same superscript upper-case letters are not statistically significantly different at $\alpha=0.05$.

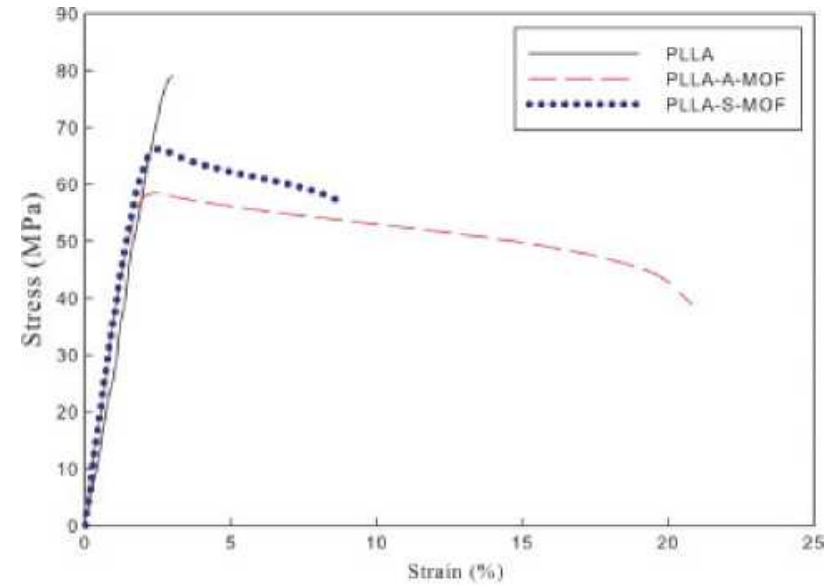

Figure 7. Stress-strain curves of PLLA, PLLA-A-MOF and PLLA-S-MOF.

Table 4. Tensile properties of PLLA, PLLA-A-MOF and PLLA-S-MOF ${ }^{a}$

$\begin{array}{lccc} & \text { Tensile } & \text { Elongation } & \text { Modulus of } \\ \text { Material } & \text { strength (MPa) at break (\%) elasticity (GPa) } & \\ \text { PLLA } & 76.9 \pm 1.5^{\mathrm{A}} & 3.6 \pm 1.5^{\mathrm{A}} & 3.0 \pm 0.3^{\mathrm{A}} \\ \text { PLLA-A-MOF } & 58.9 \pm 0.8^{\mathrm{B}} & 16.9 \pm 3.2^{\mathrm{B}} & 3.0 \pm 0.2^{\mathrm{A}} \\ \text { PLLA-S-MOF } & 66.7 \pm 1.1^{\mathrm{C}} & 9.1 \pm 2.5^{\mathrm{C}} & 3.1 \pm 0.1^{\mathrm{A}}\end{array}$

${ }^{a}$ Values in the same column with the same superscript upper-case letters are not statistically significantly different at $\alpha=0.05$.

\begin{tabular}{|c|c|c|}
\hline \multicolumn{3}{|c|}{$\begin{array}{l}\text { Table 5. Tensile strength and elongation at break of PLLA and } \\
\text { PLLA-TMA composites }{ }^{\text {a }}\end{array}$} \\
\hline Material & Tensile strength (MPa) & Elongation at break (\%) \\
\hline PLLA & $66.3 \pm 0.4^{\mathrm{A}}$ & $3.8 \pm 0.6^{A}$ \\
\hline PLLA-1\%TMA & $59.8 \pm 0.5^{B}$ & $5.8 \pm 1.1^{\mathrm{B}}$ \\
\hline $\begin{array}{l}\text { PLLA-2.5\%TMA } \\
\text { PLLA-5\% TMA }\end{array}$ & $\begin{array}{l}55.9 \pm 0.4^{\mathrm{C}} \\
52.2 \pm 0.9^{\mathrm{D}}\end{array}$ & $\begin{array}{l}5.5 \pm 0.8^{B} \\
6.5 \pm 1.0^{B}\end{array}$ \\
\hline \multicolumn{3}{|c|}{$\begin{array}{l}\text { Values in the same column with the same superscript upper-case } \\
\text { letters are not statistically significantly different at } \alpha=0.05 \text {. }\end{array}$} \\
\hline
\end{tabular}

It is also observed that the enthalpy of crystallization $\left(A H_{c}\right)$ of PLLA-A-MOF decreases from 19.6 to $3.6 \mathrm{~J} \mathrm{~g}^{-1}$ indicating a decrease in PLLA mobility and thus a decrease in the ability of the PLLA matrix to crystallize in the presence of $5 \mathrm{wt} \%$ activated MOF. No crystallization peak is observed in the cooling cycle at a cooling rate of $10{ }^{\circ} \mathrm{C} \mathrm{min}^{-1}$ for any of the materials (Fig. 6(b)).
Table 6. Molecular weight of PLLA, PLLA-A-MOF and PLLA-S-MOF

\begin{tabular}{|ccccc|} 
& PLLA resin & PLLA & PLLA-A-MOF & PLLA-S-MOF \\
\hline $\begin{array}{c}M_{n}(\mathrm{~kg} \\
\left.\mathrm{mol}^{-1}\right)\end{array}$ & $83.8 \pm 7.8^{\mathrm{A}}$ & $76.7 \pm 0.4^{\mathrm{A}},^{\mathrm{B}}$ & $67.6 \pm 4.5^{\mathrm{B}}, \mathrm{C}^{\mathrm{C}}$ & $55.6 \pm 4.3^{\mathrm{C}}$ \\
$\begin{array}{c}\mathrm{Mw}(\mathrm{kg} \\
\mathrm{mol}\end{array}$ & $\left.110.8 \pm 3.5^{\mathrm{A}}\right)$ & $105.0 \pm 0.2^{\mathrm{A}}$ & $98.6 \pm 3.2^{\mathrm{B}}$ & $83.5 \pm 2.0^{\mathrm{C}}$ \\
$\mathrm{Mw}_{\mathrm{m}} / \mathrm{Mn}$ & $1.3 \pm 0.1^{\mathrm{A}}$ & $1.4 \pm 0.0^{\mathrm{A}}$ & $1.5 \pm 0.1^{\mathrm{A}}$, & $1.5 \pm 0.1^{\mathrm{B}}$ \\
\hline
\end{tabular}

a Values in the same column with the same superscript upper-case letters are not statistically significantly different at $\alpha=0.05$.

Table 7. $\mathrm{CO}_{2}$ and $\mathrm{O}$

and PLLA-S-MOF ${ }^{\mathrm{a}}$ permeability coefficients of PLLA, PLLA-A-MOF

Permeability coefficient

(x $\left.10^{-18} \mathrm{~kg} \mathrm{~m} \mathrm{~m}^{-2} \mathrm{~s}^{-1} \mathrm{~Pa}^{-1}\right)$

$\mathrm{CO}_{2} \mathrm{O}_{2}$

$\begin{array}{lc}\text { PLLA } & 45.5 \pm 2.72^{A} 6.00 \pm 0.400^{A} \\ \text { PLLA-A-MOF } & 49.9 \pm 4.08^{A} 6.59 \pm 0.843^{A} \\ \text { PLLA-S-MOF } & 65.0 \pm 21.1^{A} 6.07 \pm 7.53^{A}\end{array}$

Values in the same column with the same superscript upper-case letters are not statistically significantly different at $\alpha=0.05$.

\section{Tensile tests}

The tensile strength of MMMs depends on various factors such as interfacial interactions, aspect ratio, dispersion of filler and thermal stability of filler. ${ }^{39}$ Fillers can also influence the crystallinity of the matrix, leading to a change in the various properties including strength, elongation, permeability, etc. PLLA is known for high tensile strength and poor flexibility. ${ }^{40}$ Elangovan et al. ${ }^{25}$ studied the surface energy, interfacial tension and spreading coefficient of PLLA and HKUST-1 MOF using contact angle measurements. Contact angles of PLLA and HKUST-1 measured using ethylene glycol were $57.1^{\circ}$ and $53.3^{\circ}$, respectively, whereas those of PLLA and HKUST-1 obtained using methylene iodide were $37.6^{\circ}$ and $45.4^{\circ}$, respectively. Those authors utilized geometric and harmonic means and obtained low interfacial tension and high work adhesion indicating good compatibility between the MOF and the PLLA. They also observed improved flexibility of PLLA with the addition of more than 1 wt\% MOF.

Stress-strain plots of PLLA, PLLA-A-MOF and PLLA-S-MOF are presented in Fig. 7. The corresponding tensile strength, elongation at break and modulus of elasticity values are presented in Table 4. The average tensile strength and elongation at break of injection-molded neat PLLA are $76.9 \mathrm{MPa}$ and 3.6\%, respectively. Bhardwajand Mohanty ${ }^{6}$ studied the modification of PLA with 


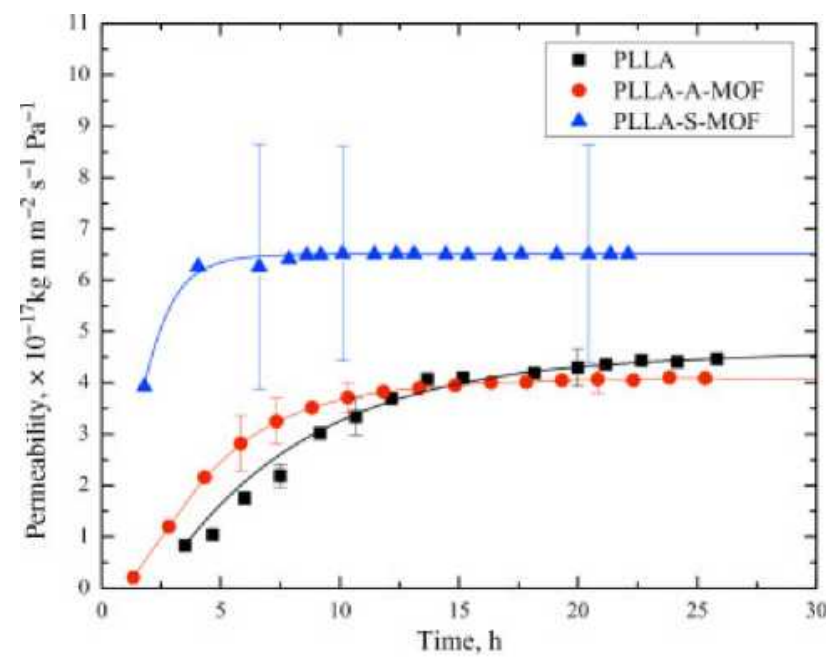

gure 8. Permeability coefficients of PLLA, PLLA-A-MOF and PLLA-S-MO

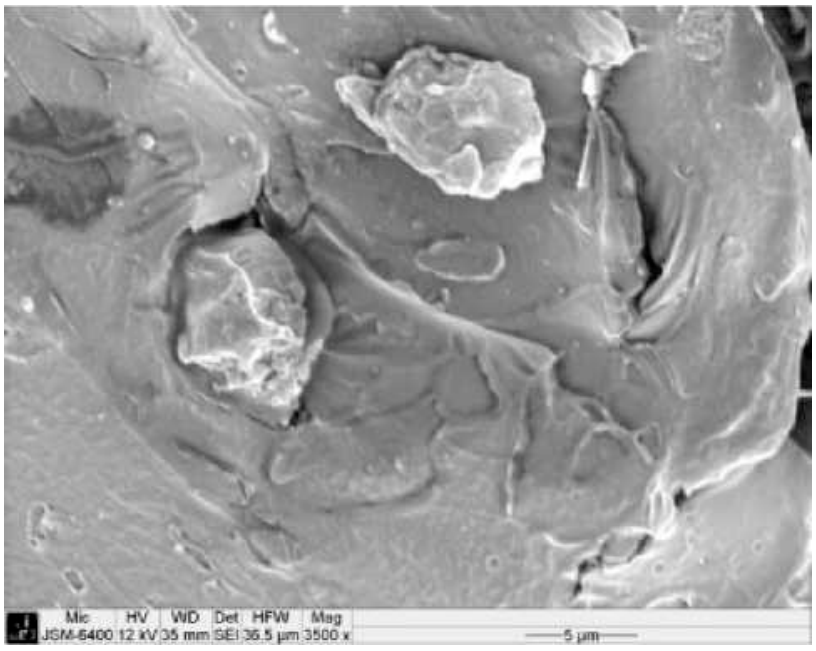

Figure 9. SEM image of PLA-A-MOF fractured surface at $12 \mathrm{kV}$ and $39 \mathrm{~mm}$ working distance.

hyberbranched polymers; they reported that PLA has a tensile strength $76.5 \mathrm{MPa}$ and elongation of $5.1 \%$. The elongation of PLLA-A-MOF and PLLA-S-MOF is 16.9 and $9.14 \%$, respectively. The improvement in the elongation of PLLA-A-MOF as compared to neat PLLA can be attributed to the good interfacial interaction between the activated MOF particles and PLLA matrix, as observed from SEM images. PLLA-S-MOF has a $300 \%$ improvement in elongation over neat PLLA. The elongation of PLLA-S-MOF is less than that of PLLA-A-MOF. The presence of water in the MOF might affect the interfacial interactions between MOF and PLLA. The tensile strength of PLLA-A-MOF decreases by around $23 \%$ as compared to neat PLLA. We observe a $13 \%$ reduction in the tensile strength of PLLA-S-MOF as compared to neat PLLA. The exact mechanism of the improved toughness of the PLLA-A-MOF and PLLA-S-MOF composites is not fully understood. Benzene-based carboxylic acid and other small-molecule polyhydric carboxylic acid ester-based plasticizers have been used as plasticizers. ${ }^{41,42}$ Wang et al. ${ }^{43}$ reported the co-polycondensation of lactic acid with TMA and noted a decrease in $T_{g}$ of the copolymer. In order to further explore this behavior, PLLA samples with 1, 2.5 and 5 wt\% TMA added, the basic constitutional unit of MOF, were produced to
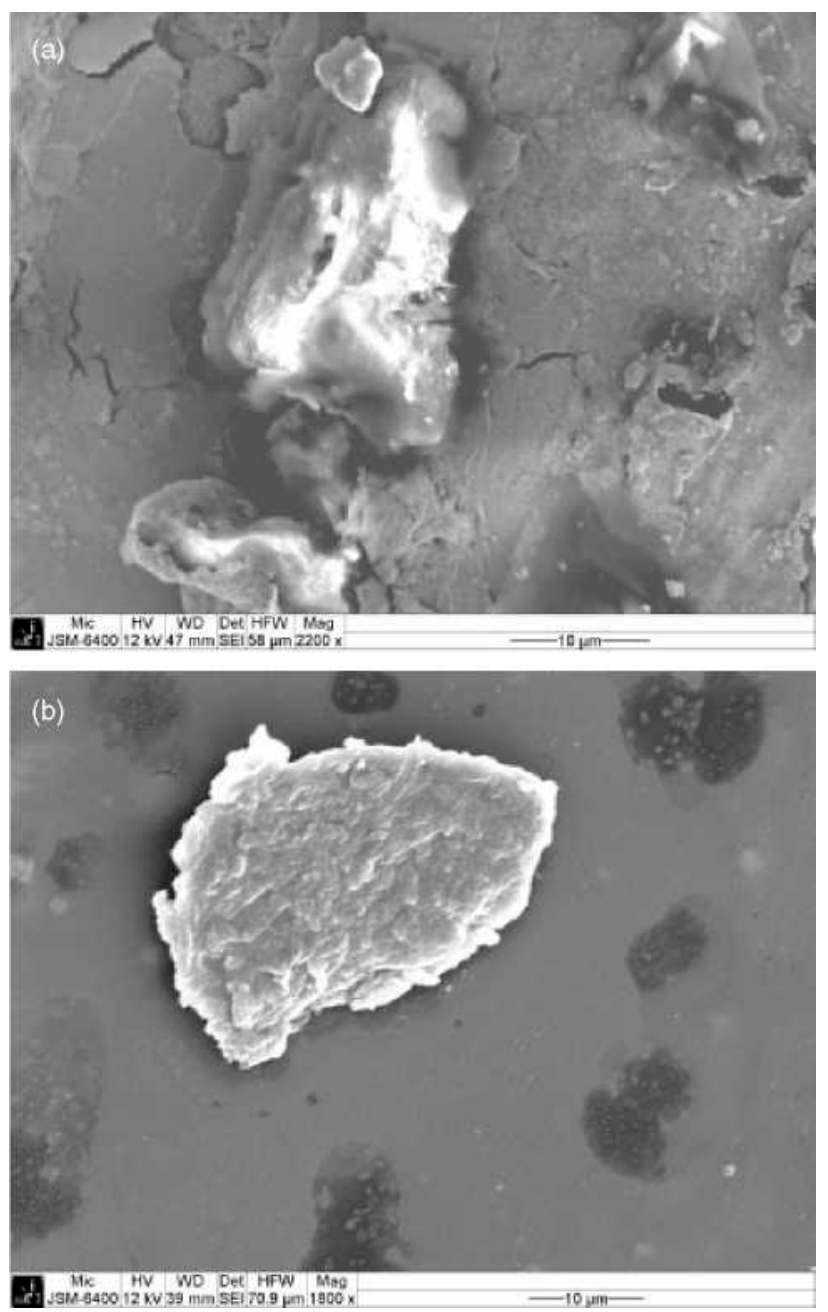

Figure 10. SEM images: (a) PLA-S-MOF fractured surface acquired at $12 \mathrm{kV}$ and $47 \mathrm{~mm}$ working distance; (b) PLA-S-MOF XRD disc surface acquired at $12 \mathrm{kV}$ and $39 \mathrm{~mm}$ working distance showing collapsed MOF particle.

isolate the possible plasticizing effect of TMA due to any possible release of benzene-1,3,5-tricarboxylate (organic linker) to PLLA after detachment from MOF during processing. Table5 shows that melt extrusion of PLLA with TMA does not substantially increase the elongation at break for PLLA samples with 1, 2.5 and $5 \mathrm{wt} \%$ TMA added. Therefore, the elongation at break improvement can be mainly attributed to the MOF particles.

\section{Gel permeation chromatography}

$M_{w}, M_{n}$ and $M_{w} / M_{n}$ of the PLLA resin, extruded PLLA, PLLA-A-MOF and PLLA-S-MOF are given in Table 6 . The $M_{w}$ values of PLLA resin, extruded PLLA, PLLA-A-MOF and PLLA-S-MOF are 110,105, 98.6 and $83.5 \mathrm{~kg} \mathrm{~mol}^{-1}$, respectively. The $6 \%$ decrease in $M_{w}$ of PLLA-A-MOF as compared to extruded PLLA can be associated with oxidative degradation. However, this $M_{w}$ reduction cannot contribute to a $470 \%$ improvement in the elongation. ${ }^{44}$ Hydrolytic degradation might be partially responsible for degradation of PLLA-A-MOF because of the minor water adsorption by the MOF before being fed into the extruder. $M_{w}$ of PLLA-S-MOF decreases by around $21 \%$ as compared to extruded PLLA. This can be ascribed to oxidative degradation plus hydrolytic degradation due to the release of the moisture from the MOF during extrusion processing. ${ }^{45}$ 


\section{$\mathrm{CO}_{2}$ and $\mathrm{O}_{2}$ permeability}

The selective permeability of a polymer or membrane is important for industrial applications such as membranes, gas separations, packaging, etc. Table 7 gives the $\mathrm{CO}_{2}$ and $\mathrm{O}_{2}$ permeability coefficients of PLLA, PLLA-A-MOF and PLLA-S-MOF. Similar CO2 and $\mathrm{O}_{2}$ permeability coefficients have been reported for PLA films. ${ }^{46}$ Although there is no statistically significant difference in the $\mathrm{CO}_{2}$ and $\mathrm{O}_{2}$ permeability coefficients among PLLA, PLLA-AMOF and PLLA-S-MOF, Fig. 8 shows that the $\mathrm{CO}_{2}$ permeability coefficients of PLLA-S-MOF have high deviation from the average values as compared to PLLA and PLLA-A-MOF. The low standard deviation for PLLA-A-MOF indicates good interfacial adhesion in the PLLA and activated MOF as supported by Fig. 9. High standard deviation values for the permeability coefficients of PLLA-S-MOF can be ascribed to the presence of voids at the interphase of PLLA and saturated MOF as observed in the SEM image (Fig. 10(a)) producing larger variations in the barrier properties of the films. Figure 10(b) shows a collapsed MOF crystal; the crystal structure may have collapsed during extrusion processing.

\section{CONCLUSIONS}

The presence of moisture in the Cu3BTC2 MOF at elevated temperatures during melt compounding processes can significantly contribute to the deterioration of the MOF crystal structure. In addition, the adsorbed moisture in the MOF particles may also accelerate the degradation of the PLLA matrix as observed from the GPC studies. As demonstrated from the tensile studies, incorporating $\mathrm{Cu}_{3} \mathrm{BTC}_{2}$ MOF improves the toughness of the PLLA matrix. Improvement in the tensile properties and $\mathrm{CO}_{2}$ permeability coefficient and SEM images of PLLA-A-MOF indicate good interfacial interactions between activated MOF and PLLA. The MOF particles have a tendency to hinder the crystallization of the polymeric matrix.

\section{ACKNOWLEDGEMENTS}

The authors thank the Composite Materials and Structure Center (CMSC), Department of Chemistry, and the Center for Advanced Microscopy at Michigan State University for allowing the use of their facilities to complete this study.

\section{REFERENCES}

1 Auras R, Harte B and Selke S, Macromol Biosci 4:835-864 (2004).

2 Soto-Valdez H, Auras R and Peralta E, J Appl Polym Sci 121:970-978 (2011).

3 Ljungberg N and Wesslen B, Biomacromolecules 6:1789-1796 (2005).

4 Zhang L, Xiong C and Deng X, Polymer 37:235-241 (1996).

5 Ray SS and Okamoto M, ProgPolymSci28 1539-1641 (2003).

6 Bhardwaj Rand Mohanty AK,Biomacromolecules8:2476-2484 (2007).

7 Rowsell JLC and Yaghi OM, MicroporMesoporMater 73:3-14 (2004).

8 Britt D, Tranchemontagne D and Yaghi OM, Proc Natl Acad Sci USA 105:11623-11627(2008).

9 FereyG, Mellot-Draznieks C, SerreC, Millange F, DutourJ, Surble S etal, Science 309:2040-2042 (2005).

10 Mueller U, Schubert M, Teich F, Puetter $\mathrm{H}$, Schierle-Arndt $\mathrm{K}$ and Pastre J, J Mater Chem 16:626-636 (2006).

11 Chuck CJ, Davidson MG, Jones MD, Kociok-Kohn G, Lunn MD and Wu S, Inorg Chem Commun 45:6595-6597 (2006).
12 Li J, Kuppler RJ and Zhou H, Chem Soc Rev 38:1477-1504 (2009).

13 Rosi NL, Eckert J, Eddaoudi M, Vodak DT, Kim J, O'Keeffe M etal, Science 300:1127-1129(2003).

14 Ananthoji R, Eubank JF, Nouar F, Mouttaki H, Eddaoudi M and Harmon JP, J Mater Chem 21:9587-9594 (2011).

15 Bordiga S, Regli L, Bonino F, Groppo E, Lamberti C, Xiao B et al, Phys Chem Chem Phys 9:2676-2685 (2007).

16 Alaerts L, Seguin E, Poelman H, Thibault-Starzyk F, Jacobs PA, Dirk E etal, ChemEurJ 12:7353-7363 (2006).

17 McArdle P and Dark R, Mciilin molecular modeling software, NUI, Galway, Ireland. More information can be found in McArdle $P$, Gilligan K, Cunningham D, Dark R and Mahon M, CrystEng Commun 6:303-309(2004).

18 Mahajan R, Burns R, Schaeffer M and Koros WJ, J Appl Polym Sci 86:881-890 (2002).

19 Yuzay IE, Auras R, Soto-Valdez H and Selke S, Polym Degrad Stab 95:1769-1777 (2010).

20 Kim S, Pechar TW and Marand E, Desalination 192:330-339 (2006)

21 Adams R, Carson C, Ward J, Tannenbaum R and Koros W, Micropor Mesopor Mater 131:13-20(2010).

22 Chung T-S, Jiang LY, Li Y and Kulprathipanja S, Prog Polym Sci 32:483-507(2007).

23 Guo H, Zhu G, Hewitt IJ and Qiu S, J Am Chem Soc 131:1646-1647 (2009)

24 Elangovan D, Nidoni U, Yuzay IE, Selke SEM and Auras R, IndEng Chem Res 50:11136-11142(2011).

25 Elangovan D, Yuzay I, Selke S and Auras R, Polym Int 61:30-37 (2012).

26 Inkinen S, Hakkarainen M, Albertsson A and Sodergard A, Biomacromolecules 12:523-532 (2011).

27 Dorgan JR, Rheology of poly(lactic acid), in Poly(Lactic Acid):Synthesis, Structures, Properties, Processing, and Applications, ed. by Auras R, Lim L-T, Selke SEM and Tsuji H. Wiley, Hoboken, NJ, pp. 125-139 (2010)

28 Schlichte K, Kratzke T and Kaskel S, Micropor Mesopor Mater 73:81 -88 (2004).

29 Huang L, Joshi KL, Van Duin ACT, Bandosz TJ and Gubbins KE, Phys Chem Chem Phys 14:11327-11332 (2012).

30 Chui SSY, Lo SM-F, Charmant JPH, Orpen AG and Williams ID, Science 283:1148-1150(1999).

31 Biemmi E, Christian S, Stock N and Bein T, Micropor Mesopor Mater 117:111-117(2009).

32 Zhou H, Green TB and Joo YL, Polymer 47:7497-7505 (2006).

33 Mathew A, Oksman Kand Sain M, J Appl Polym Sci 101:300-310 (2006)

34 Suryanegara L, Nakagaito A and Yano H, Compos Sci Technol 69:1187-1192 (2009)

35 Perego G, Cella GD and Bastioli C, J Appl Polym Sci 59:37-43 (1996).

36 Prestipino C, Regli L, Vitillo J and Bonino F, Chem Mater 18:1337-1346 (2006).

37 Ktisgens $\mathrm{P}$, Rose M, Senkovska I, Frbde H, Henschel A, Siegle S etal, Micropor Mesopor Mater 120:325-330 (2009).

38 Mustafa D, Breynaert E, Bajpe SR, Martens JA and Kirschhock CEA, Chem Commun 47:8037-8039 (2011).

39 Ghosh S, Ghosh-Bandyopadhyay S and Sain M, Composites, in Poly(Lactic Acid): Synthesis, Structures, Properties, Processing, and Applications, ed. by Auras R, Lim L-T, Selke SEM and Tsuji H. Wiley, Hoboken, NJ, pp. 293-307 (2010)

40 Lim L, Auras R and Rubino M, Prog Polym Sci 33:820-852 (2008).

41 Nakamura K, Kiyohara K, Kawabe S, Takeda A and Okubo Y, Method for manufacturing cellulose ester film. US Patent 20060069192 A1 (2006).

42 Okubo Y, Kiyohara K, Kawabe S, Takeda A, Suzuki T and Nakamura K Plasticizer, cellulose ester film, polarizing plate, and liquid crystal display. US Patent 7569259 B2 (2009).

43 Wang Z-Y, Luo Y-F ,Ye R-R and Song X-M, J Polym Res 18:499-508 (2011)

44 Perego G, Cella GD and Bastioli C, J Appl Polym Sci 59:37-43 (1996).

45 Carrasco F, Pages P, Gamez-Perez J, Santana O and Maspoch M, Polym Degrad Stab 95:116-125 (2010).

46 Auras R, Harte B, Selke S and Hernandez R, J Plast Film Sheeting 19:123-135(2003). 